\title{
Smoking and occupational allergy in workers in a platinum refinery
}

\author{
Katherine M Venables, Michael B Dally, Andrew J Nunn, Jane F Stevens, Richard Stephens, \\ Neil Farrer, Jill V Hunter, Morag Stewart, E Glyn Hughes, Anthony J Newman Taylor
}

Departments of

Occupational Medicine and Clinical Epidemiology,

National Heart and Lung

Institute, Brompton

Hospital, London

SW3 6HP

Katherine $M$ Venables, $M D$, senior lecturer

Michael B Dally, FRACP,

lecturer

Andrew J Nunn, MSC, senior

lecturer

Jane F Stevens, MRCP,

honorary research associate

Richard Stephens, data manager

Neil Farrer, BSC, research analyst

Jill V Hunter, FRCR, research fellow

Anthony J Newman Taylor, FRCP, consultant physician

Medical Department, Johnson Matthey, Royston, Hertfordshire Morag Stewart, MF́OM, group occupational physician E Glyn Hughes, FFOM, group occupational physician

Correspondence to: Dr Katherine $M$ Venables, Department of Occupational Medicine.

Br. Med J 1989:299:939-42

\section{Abstract}

Objective-To test the hypothesis that smoking increases the risk of sensitisation by occupational allergens.

Design-Historical prospective cohort study.

Setting-Platinum refinery.

Subjects-91 Workers (86 men) who started work between 1 January 1973 and 31 December 1974 and whose smoking habit and atopic state (on skin prick testing with common allergens) had been noted at joining.

Main outcome measures-Results of skin prick tests with platinum salts carried out routinely every three to six months and records of any respiratory symptoms noted by the refinery's occupational health service. Follow up was until 1980 or until leaving refinery work, whichever was earlier.

Results -57 Workers smoked and 29 were atopic; 22 developed a positive result on skin testing with platinum salts and 49 developed symptoms, including all 22 whose skin test result was positive. Smoking was the only significant predictor of a positive result on skin testing with platinum salts and its effect was greater than that of atopy; the estimated relative risks ( $95 \%$ confidence interval) when both were included in the regression model were: smokers versus non-smokers 5.05 (1.68 to $15 \cdot 2)$ and atopic versus non-atopic $2.29(0.88$ to 5.99). Number of cigarettes smoked per day was the only significant predictor of respiratory symptoms.

Conclusion-Smokers are at increased risk of sensitisation by platinum salts.

\section{Introduction}

About $5-10 \%$ of the population has asthma, and a recent report from the Tucson longitudinal study suggests that IgE dependent allergic mechanisms are important in asthma at all ages.' Little is known about the aetiology of asthma and that of related allergic conditions, such as hay fever, but studies of asthma induced by occupation are likely to be informative because occupational exposures are important "natural experiments." Smoking seems to promote the development of asthma and of specific IgE antibody in occupational settings. ${ }^{2-+}$ These studies, including our previous study of workers exposed to tetrachlorophthalic anhydride,' were cross sectional and possibly subject to survivor bias. We now report a longitudinal study in the platinum refining industry of the development of respiratory symptoms and of responses to platinum salts on skin prick testing in relation to smoking habit and atopic state.

Charged halogenated platinum salts stimulate an IgE response $e^{5}$ and cause allergic asthma. They are intermediates in the process of refining platinum, a corrosion resistant metal used as a catalyst and in jewellery. ${ }^{\times 4}$ In the past workers in refineries had a high prevalence of respiratory symptoms, ${ }^{1011}$ and asthma and rhinitis remain current problems.'2 The present study was possible because of the introduction of skin prick tests with common environmental allergens into the pre-employment medical examination in a refinery, which started in 1973 as an objective test for atopy; from 1975 atopic workers were excluded from refinery work." A preliminary study of the 1973-4 cohort showed an increased incidence of occupational allergy in atopic workers but did not examine smoking. ${ }^{13}$

\section{Methods}

We identified a cohort of 112 workers who had joined the firm between l January 1973 and 31 December 1974 as chemical process operators in the platinum group metals refineries. One vacation student and four workers with previous exposure to platinum salts were excluded, and of the remaining 107,16 left before the initial medical examination could be performed and were also excluded, leaving 91. The examination comprised a standardised health questionnaire, spirometric tests (Vitalograph), and skin prick tests. People with severe respiratory disease, a history of allergy, or low forced expiratory volumes were not employed in the refinery.

Information on age, sex, atopic state, and smoking habit at joining was obtained from the firm's medical records. Atopy was defined as one or more weals of at least $2 \mathrm{~mm}$ diameter greater than the control in skin prick tests with mixed grass pollen, house dust, and house dust mite (Bencard). The records contained information on whether the workers smoked at recruitment and their daily smoking. One worker smoked only loose tobacco, which was converted to its equivalent in cigarettes.

Skin prick tests with platinum salts were carried out on all refinery workers every three to six months. Routine screening was with freshly prepared solutions of ammonium hexachloroplatinate, sodium tetrachloroplatinite, sodium hexachloroplatinate and, in some instances, ammonium tetrachloroplatinite, all at concentrations of $10 \mathrm{~g} / \mathrm{l}$. Additional tests were carried out if indicated. A positive test result was defined as one or more weals of at least $2 \mathrm{~mm}$ diameter greater than the control. The date of the first positive test result or, in the absence of a positive result, the last negative test result was noted.

The firm's medical records were also reviewed for the occurrence of symptoms. These were defined as one or more of: (a) a diagnosis of allergy to platinum salts made by the firm's doctor (asthma except in two cases of dermatological allergy), (b) a memorandum from a nurse to a doctor that a worker or a worker's supervisor had requested medical examination because of respiratory symptoms possibly related to work, (c) a record of attendance at the firm's clinic with respiratory symptoms (bronchitis, asthma, wheeze, 
chest tightness, or unexplained cough, but excluding minor symptoms attributable to upper respiratory tract infection), and $(d)$ a sickness certificate suggesting respiratory symptoms (as defined above). The date of the first symptoms was used in the analysis.

The workers were followed up until 30 April 1980 or until leaving refinery work, whichever was earlier. Leaving refinery work was defined as leaving the firm or transferring to other work in the firm. The proportional hazards regression model ${ }^{14}$ was used to identify factors at joining that predicted subsequent symptoms or a positive skin test result to platinum salts. Factors that predicted leaving refinery work were also identified. The factors considered in the analysis were: age at joining, sex, date of joining (days from 1 January 1973), presence or absence of atopy, whether the worker smoked or not, consumption of cigarettes (number/day), and an atopy $\times$ smoking interaction term. Statistical significance was taken to be $\mathrm{p}<0.05$.
TABLE 1-Characteristics of cohort at joining firm

\begin{tabular}{ll}
\hline & No(", $(1)$ \\
\hline Subjects & 91 \\
Ratio men:women & $86: 5$ \\
Age (years): & \\
$15-24$ & $27(30)$ \\
$25-34$ & $37(41)$ \\
$35-44$ & $22(24)$ \\
$45-54$ & $5(5)$ \\
Presence of atopy* & $29(33)$ \\
Smoker & $57(63)$ \\
Consumption of & \\
cigarettes/day*: & \\
$1-10$ & $12(14)$ \\
$\geqslant 11$ & $40(47)$ \\
\end{tabular}

*Information not available on atopy for three subjects, smoking for one. and cigarelte consumption for six.

\section{Results}

Most of the 91 workers were young men, a third were atopic and almost two thirds smoked (table I). Turnover was rapid in the early years of employment; two thirds of the workers had left refinery work by one year and over $90 \%$ by four years.

Forty nine workers reported respiratory symptoms (as defined above): in 21 allergy to platinum salts was diagnosed, 30 were the subject of a memorandum about symptoms related to work, 40 attended the clinic with respiratory symptoms, and 16 took sick leave because of respiratory symptoms. Twenty two developed a positive skin test result to platinum salts and all 22 also reported symptoms, not necessarily at the same time; the interval ranging from symptoms
TABLE II - Interval between respiratory symptoms and positive skin test result to platinum salts

\begin{tabular}{|c|c|c|c|c|c|c|c|c|c|c|c|c|}
\hline \multirow[b]{2}{*}{ Midpoint of interval (months) } & \multicolumn{5}{|c|}{$\begin{array}{c}\text { Symptoms before positive skin } \\
\text { test result }\end{array}$} & \multicolumn{7}{|c|}{$\begin{array}{l}\text { Positive skin test result before } \\
\text { symptoms }\end{array}$} \\
\hline & $>12$ & 12 & 9 & 6 & 3 & 0 & 3 & 6 & 9 & 12 & $>12$ & Total \\
\hline No of workers & 2 & 0 & 1 & 1 & 4 & 9 & 1 & 1 & 1 & 1 & 1 & 22 \\
\hline
\end{tabular}

TABL.F. III - Incidence of symptoms and of positive results on skin testing with platinum salts in refiner workers

\begin{tabular}{|c|c|c|c|c|c|c|c|}
\hline & \multicolumn{7}{|c|}{ Follow up period (months) } \\
\hline & $\leqslant 3$ & $>3-6$ & $>6-12$ & $>12-24$ & $>24-48$ & $>48^{\star}$ & Total ${ }^{\star}$ \\
\hline \multicolumn{8}{|c|}{ Positiate skin test result } \\
\hline No of workers at start of period & 84 & 51 & 38 & 20 & 12 & 5 & 84 \\
\hline Person months in period & $167 \cdot 8$ & $130 \cdot 1$ & $163 \cdot 0$ & $192 \cdot 5$ & $154 \cdot 0$ & $110 \cdot 3$ & $917 \cdot 6$ \\
\hline No of cases in period & 2 & 5 & 9 & 4 & 2 & 0 & 22 \\
\hline Incidence rate $\left(\omega_{0}\right)$ & $1 \cdot 2$ & $3 \cdot 8$ & $5 \cdot 5$ & $2 \cdot 1$ & $1 \cdot 3$ & & $2 \cdot 4$ \\
\hline \multicolumn{8}{|c|}{ Symptoms } \\
\hline No of workers at start of period & 91 & 47 & 32 & 17 & 6 & 2 & 91 \\
\hline Person months in period & $210 \cdot 1$ & $111 \cdot 7$ & $140 \cdot 1$ & $117 \cdot 3$ & $84 \cdot 9$ & $59 \cdot 1$ & $723 \cdot 3$ \\
\hline No of cases in period & 20 & 10 & 10 & 7 & 2 & 0 & 49 \\
\hline Incidence rate $(\%)$ & $9 \cdot 5$ & $9 \cdot 0$ & $7 \cdot 1$ & $6 \cdot 0$ & $2 \cdot 4$ & & $6 \cdot 8$ \\
\hline
\end{tabular}

*Up to 30 April 1980.

TABILE IV - Summary of proportional hazards regression analysis to identify factors at joining that predicted subsequent symptoms or a positize skin test result to platinum salts in refinery worker

\begin{tabular}{|c|c|c|c|}
\hline Outcome & Predictor & $\begin{array}{l}\text { Regression coefficient } \\
\text { (SE) }\end{array}$ & $\begin{array}{l}\text { Risk estimate } \\
\text { (95\% confidence interval) }\end{array}$ \\
\hline \multirow[t]{2}{*}{ Positive skin test result } & Smoker $v^{\prime}$ non-smoker & $1.54(0.56)$ & $4 \cdot 66(1.55 t 014 \cdot 0)$ \\
\hline & $\begin{array}{l}\text { Smoker } a \text { non-smokert } \\
\text { Atopic a' non-atopict }\end{array}$ & $\begin{array}{l}1.62(0.56) \\
0.83(0.49)\end{array}$ & $\begin{array}{l}5 \cdot 05(1.68 \text { to } 15 \cdot 2) \\
2 \cdot 29(0.88 \text { to } 5.99)\end{array}$ \\
\hline \multirow[t]{2}{*}{ Symptoms } & Cigarettes smoked/day & $0 \cdot 06+(0 \cdot 017)$ & $1.89(1.36$ to 2.64$)$ per 10 cigarettes \\
\hline & Smoker $v$ non-smoker $\ddagger$ & $0.99(0.32)$ & $2.69(1.43$ to 5.05$)$ \\
\hline
\end{tabular}

*Considered alone in model.

tSmoking and atopy considered together in modet.

tPresented for comparison only. Cigarettes/day was the only variable that significantly predicted sumptoms.
468 days before the positive test result to 476 days after (median eight days before) (table II). All of the 22 with a positive skin test result to platinum salts and most (45/48) of those with symptoms left refinery work (fig 1). The incidence of respiratory symptoms and of a positive result on skin testing with platinum salts were highest in the first year of work (table III). No symptoms or positive skin test results were recorded after four years.

Proportional hazards regression analysis showed that smoking was the single most important predictor of a positive skin test result to platinum salts (table IV and fig 2), the risk in smokers being four to five times that in non-smokers. There was a suggestion that atopy was associated with a positive skin test result to platinum salts $(\mathrm{p}<0 \cdot 1)$. The other smoking variable, consumption of cigarettes, was the single most important predictor of symptoms (table IV and fig 2).

Age was the most important predictor of leaving refinery work (younger workers had a higher turnover than older workers), and smoking was the next best predictor. The risk of leaving was 1.75 times greater in smokers than non-smokers $95 \%$ confidence interval 1.09 to $2 \cdot 80$ ) after taking account of age.

\section{Discussion}

Our main finding was that smokers had an increased risk of occupational allergy. Smoking predated allergy, the association was strong, and there was a suggestion of a dose-response gradient, observations that are consistent with a causal relation. The association cannot readily be explained by recording bias as smoking habit was recorded when workers joined the refinery and the outcomes were noted during 1973-8, when there was little interest in smoking as a risk factor for allergy. The risk of developing a positive skin test result to platinum salts was fourfold to fivefold greater in smokers than non-smokers (table IV), similar to the fourfold to fivefold increased risks in smokers noted for specific IgE antibodies to tetrachlorophthalic anhydride ${ }^{2}$ and to ispaghula ${ }^{3}$ and for a positive skin test result to green coffee. ${ }^{3}$ A relative risk of such magnitude cannot easily be explained by the presence of an unrecorded confounding variable. The risk to smokers of developing symptoms was less, about twofold greater (table IV), which may be because the cases of occupational asthma were diluted by cases of respiratory symptoms with other causes; it is, however, consistent with the risk of occupational asthma in smokers who process snow crabs. ${ }^{+}$

An increased risk to smokers has been found in other groups of platinum refinery workers, strengthening the assumption of a causal relation. The rate of development of a positive skin test result to platinum salts has been higher in smokers than non-smokers among the recent employees of this refinery ( $M$ Stewart, unpublished results). Linnett reported similar findings in a refinery in South Africa and noted an increase in risk with increasing cigarette consumption. ${ }^{15}$ Our finding that the number of cigarettes smoked a day was significantly associated with the development of respiratory symptoms might suggest a dose-response gradient but was not observed for a positive skin test result to platinum salts and might have occurred because the number of cigarettes per day was correlated with whether a worker smoked or not. Holt has suggested that light smoking may have greater effects on the immune system than heavy smoking. ${ }^{10}$

Several studies in animals have shown that inhaled smoke and other irritants are adjuvants for experimental sensitisation. Experimental smoking potentiated the IgE response in rats to inhaled, but not subcutaneous, ovalbumin ${ }^{17}$; exposure to ozone 


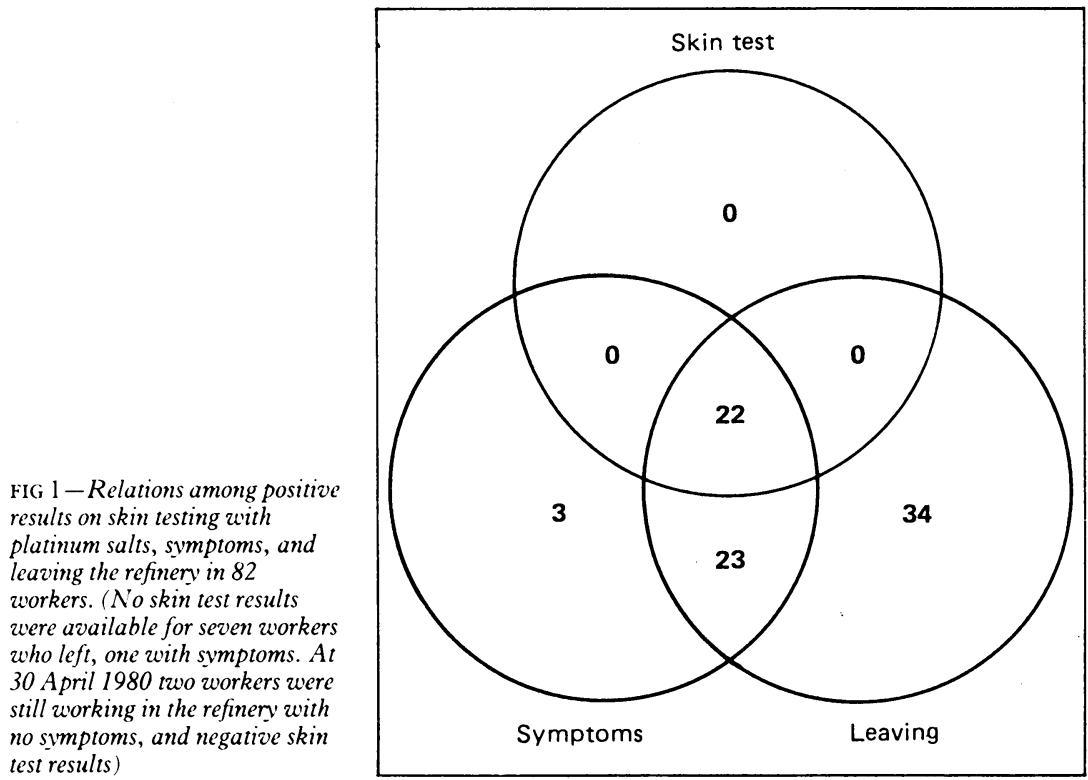
test results)
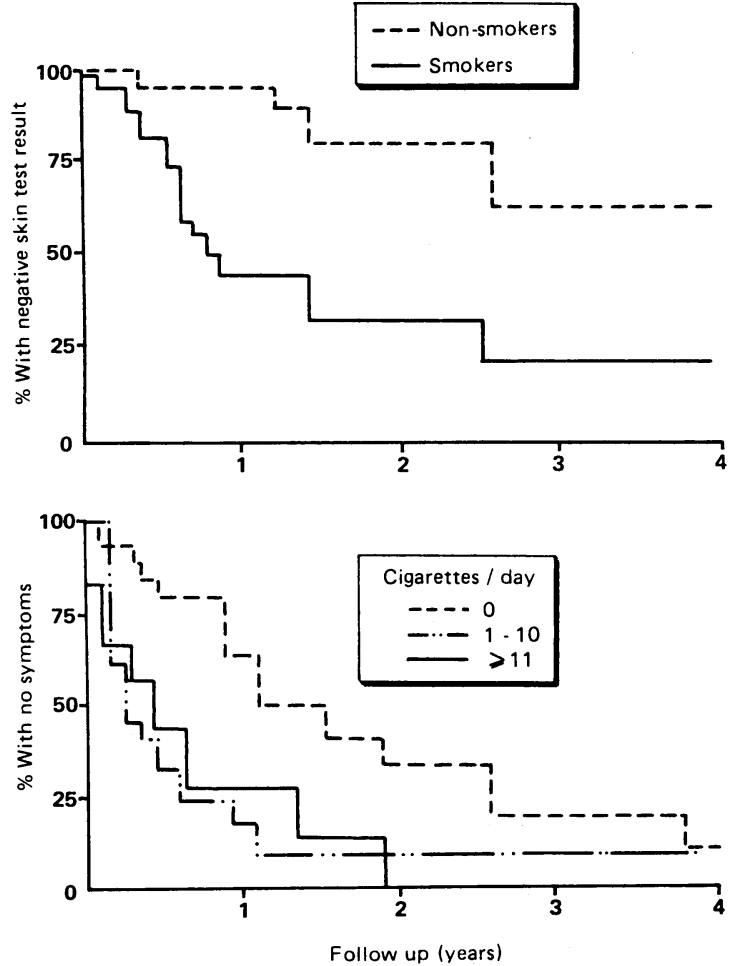

enhanced sensitisation to inhaled platinum salts in monkeys ${ }^{1 x}$; ozone, nitrogen dioxide, and sulphur dioxide potentiated sensitisation to ovalbumin in guinea pigs ${ }^{14}$; and diesel exhaust particulates potentiated the IgE response in mice to intranasal ovalbumin. ${ }^{20}$ The adjuvant effect of smoking may be explained by suppression of IgE regulatory $T$ cell function. ${ }^{16}$ Zetterstrom et al ${ }^{17}$ suggested that the selective effect of smoke on sensitisation by inhalation implies that increased mucosal permeability induced by smoke allows inhaled antigen to cross the bronchial mucosa. ${ }^{1:}$ Both mechanisms are plausible, and they may act together.

The risk from atopy was smaller than that for smoking and was not significant after taking account of smoking. The cohort may have been too small to detect the weaker effect of atopy. People with a history of allergy were not employed in the refinery and thus a few highly susceptible atopic subjects may have been excluded, leading to underestimation of the risk from atopy. The incidence of occupational allergy in the firm has fallen since 1975. 'The exclusion of job applicants with atopy from 1975 and changing smoking habits over time may have contributed to the reduced incidence of occupational allergy, but improved engineering controls, which were also introduced in the mid-1970s, are a more likely explanation.

Our study confirmed the high incidence rate of occupational allergy in the platinum refining industry in the mid-1970s. It was probably between 2.4 and 6.8 per 100 person months, the estimates for a positive skin test result to platinum salts and for symptoms (table III). The rate for a positive skin test result to platinum salts is an underestimate because the high labour turnover, not unusual for the mid-1970s, meant that some positive results might have been missed. The rate for symptoms is an overestimate because, even though some symptoms would have been missed, we included respiratory symptoms from all causes and fewer than half were diagnosed as allergy to platinum salts. The cohort was too small to justify calculating incidence rates within different occupations in the refinery. The study suggests that the incidence of occupational allergy to platinum salts is highest in the first year of exposure and falls appreciably in the second and subsequent years. Symptoms and positive results on skin testing were not necessarily coincident, and the interval could be as much as a year or more. Similar findings were obtained when only symptoms of diagnosed allergy to platinum salts were considered. ${ }^{13}$

The increased risk of occupational allergy in smokers and the adjuvant effect of a range of inhaled irritants in animals could mean that in humans exposure to non-specific dusts, gases, and vapours might increase the risk of allergic disease. A similar suggestion was made recently about pollution by diesel exhaust particulates and an increase in prevalence of allergic rhinitis in Japan caused by pollens. ${ }^{20} \mathrm{~A}$ retrospective study has suggested that maternal smoking increases the risk of asthma and other allergic disease in infancy. ${ }^{21}$ Several studies, reviewed by Holt, ${ }^{16}$ have shown that smokers have higher total serum concentrations of IgE than non-smokers. The adjuvant effect may be confined to IgE dependent allergic mechanisms as some types of occupational asthma, for example those due to red cedar wood and isocyanates, are not, according to present evidence, closely associated with IgE antibody specific for occupation and also have not so far been associated with smoking. ${ }^{22}$ It is also possible that the adjuvant effect is evident only after exposure to novel antigen, such as occurs in infancy, with new occupational exposures, and in animal experiments.

We thank the occupational health nurses of the company for help in abstracting data, and Mr J Upton for help in data analysis. JU was supported by the Camilla Samuel Fund and MBD by a grant from Johnson Matthey.

1 Burrows B, Martinez FD, Halonen M, Barbee RA, Cline MG. Association of asthma with serum IgE levels and skin-test reactivity to allergens. $N$ Engl Med 1989;320:271-6.

2 Venables KM, Topping MD, Howe W, Luczynska CM, Hawkins R, Newman Taylor AJ. Interaction of smoking and atopy in producing specific IgE antibody against a hapten protein conjugate. Br Med f 1985;290:201-4.

3 Zetterstrom O, Osterman K, Machado L, Johansson SGO. Another smoking hazard: raised serum IgE concentration and increased risk of occupational hazard: raised serum $\operatorname{lgE}$ concentraic

4 Cartier A, Malo J-L, Forest F, et al. Occupational asthma in snow crab-processing workers. $\mathcal{F}$ Allergy Clin Immunol 1984;74:261-9.

5 Cleare MJ, Hughes EG, Jacoby B, Pepys J. Immediate (type I) allergic responses to platinum compounds. Clin Allergv 1976;6:183-95.

6 Pepys J, Parish WE, Cromwell O, Hughes EG. Passive transfer in man and the monkey of type I allergy due to heat labile and heat stable antibody to complex salts of platinum. Clin Allergy 1979;9:99-108.

7 Pepy's J, Pickering CAC, Hughes EG. Asthma due to inhaled chemical agents - complex salts of platinum. Clin Allergv 1972;2:391-6.

Hunter D. The diseases of occupations. 6th ed. London: Hodder and Stoughton. 1978:460-3.

9 Hughes EG. Medical surveillance of platinum refinery workers. I Soc Occup Med 1980;30:27-30.

10 Hunter D, Milton R, Perry KMA. Asthma caused by the complex salts of platinum. Br f Ind Med 1945;2:92-8. 


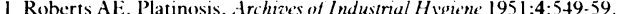

2 Industrial Injuries Advisory Council. Occupational asthma London: HMSO, 1981 (Cmnd 8121.

13 Dally MB, Hunter JV, Hughes EG, Stewart M. Newman Tavkor AJ. Hypersensitivity to platinum salts: a population studv. Am Rev Respir D 1980;121:230a.

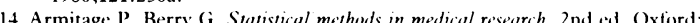
Blackwell, 1987:435-8.

15 Linnett PJ. Platinum salt sensitivity: a review of the health aspects of platinum refining in South Africa. Fournal of the Mine. Medical Officers Association of South Africa 1987;63(433):24-8. $1987 ; 42: 2+1-9$

17 Zetterstrom O, Nordvall SL, Bjorksten B, Ahlstedt S, Stelander M. Increased IgE antibody responses in rats exposed to tobacco smoke. 7 Allergy Clin Immunol 1985;75:594-8.
I8 Biagini RE, Meorman W'J, Lewis TR, Bernstein IL. Ozone enhancement of pla

a the experimentally ind Dis $1970: 102:+38-43$

20 Takafuji S, Suzuki S, Koizumi K, el al. Diesel-cxhaust particulates inoculated by the intranasal routc have an adjuvant activity for IgE production in mice. 7. Allergy Clin Immunol 1987;79:639-45.

21 Magnusson CGiM. Maternal smoking influences cord serum IgE and Ig1) levels and increases the risk for subsequent infant allergy. F. Allergy Clin Immunol 1986;78:898-9(1)4.

22 Chan-Ycung M, Lam S. Occupational asthma. Am Rev Respir Dis 1986;133 $686-703$

Accepted 2 August 1989
16 Holt P(i. Immune and inflammatory function in cigarette smokers. Thorax

\section{Acute and chronic arterial and venous effects of captopril in congestive cardiac failure}

\author{
S Capewell, D Taverner, W J Hannan, A L Muir
}

\section{Abstract}

Objective-To determine whether captopril alters peripheral venous tone in patients with congestive cardiac failure.

Design-Open study of patients at start of captopril treatment and three months later.

Setting-A hospital gamma camera laboratory.

Patients-16 Men with congestive cardiac failure in New York Heart Association class II or III, aged 57-73.

Interventions-Patients were initially given $500 \mu \mathrm{g}$ sublingual glyceryl trinitrate followed by $25 \mathrm{mg}$ oral captopril. The study was then repeated after three months' captopril treatment.

Main outcome measures-Previously validated non-invasive radionuclide techniques were used to measure changes in central haemodynamic variables and peripheral venous volumes in the calf.

Results-After $25 \mathrm{mg}$ captopril there were falls in blood pressure and relative systemic vascular resistance and increases in cardiac index and lef ventricular ejection fraction. This was accompanied by a $16 \%$ increase in peripheral venous volume $(95 \%$ confidence interval $13.4 \%$ to $18.4 \%, p<0.01$ ), which compared with an $11 \%$ increase after $500 \mu \mathrm{g}$ glyceryl trinitrate $(10 \%$ to $12 \%, \mathrm{p}<0.01)$. Eleven patients were restudied after three months' continuous treatment with captopril. The resting venous volume was higher than it had been initially, by about $10 \%$, and increased by a further $8.4 \%$ after $25 \mathrm{mg}$ captopril $(5 \cdot 4 \%$ to $11 \cdot 4 \%, \mathrm{p}<0.05)$.

Conclusions-Captopril is an important venodilator. Venous and arterial dilatation are produced short term and during long term treatment.
University Department of Medicine, Royal Infirmary, Edinburgh EH3 9YW $\mathrm{S}$ Capewell, MD, lecturer in medicine

D Taverner, MRCP, lecturer in medicine

W J Hannan, PHD, principal physicist

A L Muir, FRCP, reader in medicine

Correspondence to: Dr S Capewell, Department of Tuberculosis and Chest Diseases, Llandough Hospital, Penarth, South Glamorgan CF6 1XX.

Br Med f 1989;299:942-5 hydralazine. ${ }^{x y}$ Furthermore, reduced cardiac filling pressures persist during long term treatment with captopril. Although this has been attributed to venodilatation, ${ }^{2}$ it may simply reflect an improvement in ventricular diastolic performance. 'Studies of the venous response to captopril in heart failure are sparse and conflicting. Using venous occlusion plethysmography, Cowley et $a l^{10}$ and Awan et al observed that venous tone in the forearm fell within an hour after the first dose of captopril by $15 \%$ and $50 \%$ respectively. Faxon et al showed "a small rise" in the maximal venous volume in the calf after captopril, ${ }^{1 .}$ whereas Olivari et al found no significant changes." These studies assessed only the immediate effect of captopril, and there is no information about the venous changes after prolonged treatment. We therefore investigated the central and venous responses to captopril, comparing them with those after glyceryl trinitrate, a known venodilator, ${ }^{\prime}$ in patients with severe congestive cardiac failure at the start and after three months of captopril treatment.

\section{Methods}

Sixteen men with moderate or severe congestive cardiac failure secondary to ischaemic heart disease were studied at the start of captopril treatment; 11 were available for restudy after three months' treatment (table I). All 16 had symptoms and were in New York Heart Association class II or III, with impaired left ventricular function (mean left ventricular ejection fraction of $0 \cdot 19$ (table I)). They required daily frusemide at a mean dose of $116 \mathrm{mg}$.(range $80-160 \mathrm{mg}$ ), and four were also taking digoxin at a mean daily dose of $0.19 \mathrm{mg}$. The 11 men who were restudied had a mean age of 64 (range 57-73), were all in sinus rhythm, and had been clinically stable for at least one month before the study.

None of the patients suffered from more than occasional angina and none had received treatment with a vasodilator, such as long acting nitrates or calcium antagonists, within seven days before the study. Patients with severe hypertension or hypotension (systolic blood pressure $>180$ or $<90 \mathrm{~mm} \mathrm{Hg}$ ), who had had an acute myocardial infarction within three months and had clinically important liver, lung, renal, or cardiac valve disease were excluded. Five patients did not complete the study: two had a severe hypotensive reaction to the first dose and were not continued on captopril, and three started long term treatment but died one, two, and six weeks afterwards. Two deaths occurred at home, one being sudden and one being diagnosed clinically as due to an acute pressures fall, presumably indicating a reduction in preload. ${ }^{+}$This response resembles that observed after venodilators such as isosorbide dinitrate ${ }^{7}$ and sodium nitroprusside, ${ }^{8}$ rather than arterial vasodilators such as 